\title{
Lipoplex-based targeted gene therapy for the suppression of tumours with VEGFR expression by producing anti-angiogenic molecules
}

\author{
Shu-Yi Ho ${ }^{1 \dagger}$, Pin-Rong Chen ${ }^{2 \dagger}$, Chia-Hung Chen ${ }^{3 \dagger}$, Nu-Man Tsai ${ }^{4,5}, Y u-H s i n ~ L i n{ }^{6}$, Chen-Si Lin ${ }^{7,8}$, \\ Cheng-Hsun Chuang ${ }^{2}$, Xiao-Fan Huang ${ }^{4,9}$, Yi-Lin Chan ${ }^{10}$, Yen-Ku Liư ${ }^{2}$, Chen-Han Chung ${ }^{2,11}$, \\ Shun-Long Weng ${ }^{12,13^{*}}$ and Kuang-Wen Liao ${ }^{1,2,6,14,15^{*}}$
}

\begin{abstract}
Background: The anti-angiogenic fusion protein RBDV-IgG1 Fc (RBDV), which comprises the receptor-binding domain of vascular endothelial growth factor-A (VEGF-A), has shown antitumour effects by reducing angiogenesis in vivo. This study used the cationic lipoplex lipo-PEG-PEI-complex (LPPC) to simultaneously encapsulate both the RBDV targeting protein and the RBDV plasmid (pRBDV) without covalent bonds to assess VEGFR targeting gene therapy in mice with melanoma in vivo.

Results: LPPC protected the therapeutic transgene from degradation by DNase, and the LPPC/RBDV complexes could specifically target VEGFR-positive B16-F10 cells both in vitro and in vivo. With or without RBDV protein-targeting direction, the pRBDV-expressing RBDV proteins were expressed and reached a maximal concentration on the 7th day in the sera after transfection in vivo and significantly elicited growth suppression against B16-F10 melanoma but not IgG1 control proteins. In particular, LPPC/pRBDV/RBDV treatment with the targeting molecules dramatically inhibited B16-F10 tumour growth in vivo to provide better therapeutic efficacy than the treatments with gene therapy with IgG1 protein targeting or administration of a protein drug with RBDV.
\end{abstract}

Conclusions: The simultaneous combination of the LPPC complex with pRBDV gene therapy and RBDV protein targeting might be a potential tool to conveniently administer targeted gene therapy for cancer therapy.

Keywords: LPPC, Gene therapy, Anti-angiogenesis, RBDV, VEGFR

\section{Background}

As the sizes of tumours increase to more than $1-2 \mathrm{~mm}^{3}$, the microenvironments of the tumour will become

*Correspondence: 4467@mmh.org.tw; liaonms@mail.nctu.edu.tw 'Shu-Yi Ho, Pin-Rong Chen and Chia-Hung Chen contributed equally to this work

${ }^{1}$ Department of Biological Science and Technology, National Chiao Tung University, Hsinchu City 30068, Taiwan, ROC

${ }^{12}$ Department of Medicine, MacKay Medical College, New Taipei City 25245, Taiwan, ROC

Full list of author information is available at the end of the article hypoxic to threaten tumour growth. At this time, the tumours will disrupt the balance between pro- and anti-angiogenic factors within the microenvironment of tumour areas to facilitate angiogenesis $[1,2]$. Under such conditions, various pro-angiogenic factors, including growth factors and proinflammatory cytokines, increase their expression to promote angiogenesis, which contributes to tumour growth, persistence, and metastasis [3-5]. Without such angiogenesis, the tumours will undergo necrosis [6].

(C) The Author(s) 2020. This article is licensed under a Creative Commons Attribution 4.0 International License, which permits use, sharing, adaptation, distribution and reproduction in any medium or format, as long as you give appropriate credit to the original author(s) and the source, provide a link to the Creative Commons licence, and indicate if changes were made. The images or other third party material in this article are included in the article's Creative Commons licence, unless indicated otherwise in a credit line to the material. If material is not included in the article's Creative Commons licence and your intended use is not permitted by statutory regulation or exceeds the permitted use, you will need to obtain permission directly from the copyright holder. To view a copy of this licence, visit http://creativeco mmons.org/licenses/by/4.0/. The Creative Commons Public Domain Dedication waiver (http://creativecommons.org/publicdomain/ zero/1.0/) applies to the data made available in this article, unless otherwise stated in a credit line to the data. 
Thus, interference in the VEGF-VEGFR axis signalling pathway to inhibit angiogenesis has been under development to suppress both tumour growth and metastasis due to all of the angiogenic factors, with VEGF playing the most crucial roles [7-10]. For tumour therapy, bevacizumab [an anti-VEGF humanized monoclonal antibody (mAb)], aflibercept (an anti-VEGF fusion protein) and ramucirumab (an anti-VEGFR-2 human $m A b$ ) have been developed and shown to inhibit the VEGF-VEGFR interaction and indeed provides an excellent therapeutic effect in patients with tumours [11-13] and in experimental animal models [14-16]. However, certain obstacles exist in the clinical trials of anti-angiogenic protein-based therapies. First, some acute and unusual toxicities have been observed, including gastrointestinal perforation and arterial thromboembolic complications [17-19]. Second, clinical results show that protein drugs need repeated administration to maintain a therapeutic concentration in tissues due to their relatively short half-lives. Third, pharmacokinetic studies have also shown that the administration of therapeutic proteins might not be optimal in the body, as they cannot maintain a continuous stable elevated level [20-22]. Therefore, high-dose administration of therapeutic proteins is required for a good therapeutic effect, especially for anti-angiogenesis proteins. Finally, the prices for the production and purification of protein drugs still cannot be lowered, and protein drugs are more expensive than traditional chemo drugs, which causes an economic burden.

Therefore, gene therapy for the continued expression of anti-angiogenic proteins has become an attractive approach, in which non-viral vectors may provide several advantages, such as being non-pathogenic, less immunogenic, not limited to transgene size, of low cost, and simple to prepare [23-25]. Within the non-viral gene delivery system, lipoplexes have become popular for cancer gene therapy. Moreover, lipoplexes are modified with various targeting tools to specifically deliver a drug to its target [26-31].

In cancer, the difference in the densities of endothelial cells between tumour tissues and normal tissues may be 50 -fold, and the density could be a tumour-specific target that makes it easily accessible for drug administration [32]. RBDV-IgG1 Fc (RBDV), a recombinant fusion protein constructed by the receptor-binding domain of VEGF-A and the Fc fragment of human IgG1, can suppress tumour growth and angiogenesis in C57BL/6 mice after administration [33].

However, using RBDV as an anti-angiogenic protein also has its drawbacks, similar to other anti-angiogenic protein-based therapies. Hence, we used the cationic lipoplex (LPPC) as the vector for targeted gene therapy.
LPPC is composed of two polymers, polyethylene glycol (PEG) and polyethylenimine (PEI), and two lipids, 1,2-Dioleoyl-sn-glycero-3-phosphocholine (DOPC) and 1,2-dilauroyl-sn-glycero-3-phosphocholine (DLPC). It has been shown that LPPC can be complexed with proteins in a non-covalent linkage manner, and the bound proteins which still retain their biological activity cannot be displaced by unbound proteins [34,35]. With this property, LPPC has been used as a vector for targeted tumour therapy in combination with Herceptin [36]. However, the use of LPPC for targeting gene therapy has been still unknown.

In this study, LPPC simultaneously encapsulated an RBDV plasmid (pRBDV) and targeted the RBDV protein to achieve specific targeted gene therapy for melanoma. The results showed that LPPC-based gene therapy could contribute to a better therapeutic efficacy than administration of protein drugs alone.

\section{Results}

\section{The characteristics of the LPPC/DNA complexes}

The gel retardation assay showed that the LPPC particles encapsulated different amounts of plasmid DNAs to form complexes and are trapped in the loading wells of the agarose gel (Fig. 1a, lanes 2-5). Furthermore, $0.6 \%$ SDS disrupts the liposomal complex and releases plasmid DNAs, which are visible as bands on the gel (Fig. 1a, lanes 6-9). Additionally, the maximal DNA binding capacity of $50 \mu \mathrm{g}$ LPPC was approximately $12 \mu \mathrm{g}$ (Fig. 1b). Moreover, the particle diameters or surface charges of different LPPC complexes were examined by dynamic light scattering. Table 1 shows that the average size of LPPC is $197.1 \pm 17.8 \mathrm{~nm}$, and the binding of DNA, protein, or PEG to LPPC increases the particle size of LPPC from $197.1 \pm 17.8$ to $527.5 \pm 83.4 \mathrm{~nm}$. In addition, the surface charge of the LPPCDNA complexes and LPPC/RBDV complexes decreased from $43.2 \pm 1.4$ to $4.9 \pm 2.0 \mathrm{mV}$.

The stability of the LPPC/DNA complex was examined for DNase I degradation, and the results indicate that DNase I can fully degrade the DNA released from the LPPC complexes but not the DNAs on the LPPC complexes (Fig. 1c, lanes 3-4). These results reveal that LPPC protects DNAs from DNase I degradation. Moreover, the LPPC complexes that inserted hrGFP plasmids can transfect B16-F10 cells, and the transfectant can express green fluorescence in a dose-dependent manner (Fig. 1d). Furthermore, the fluorescence of these transfectants was determined by flow cytometry to demonstrate the efficiency and expression of the transfection. The results show that LPPC can transfect the plasmid DNAs into the cells, and the transfectants can express the transgene in a dose-dependent manner (Fig. 1e, f). 


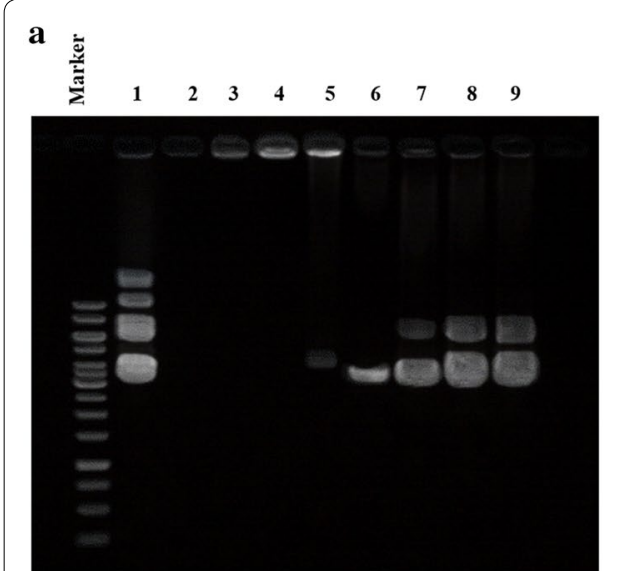

$\mathbf{b}$

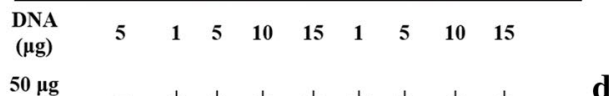

d

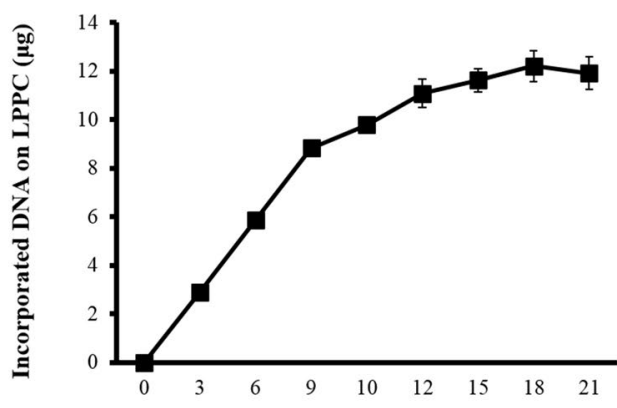

LPPC

$0.6 \%$

SDS

c
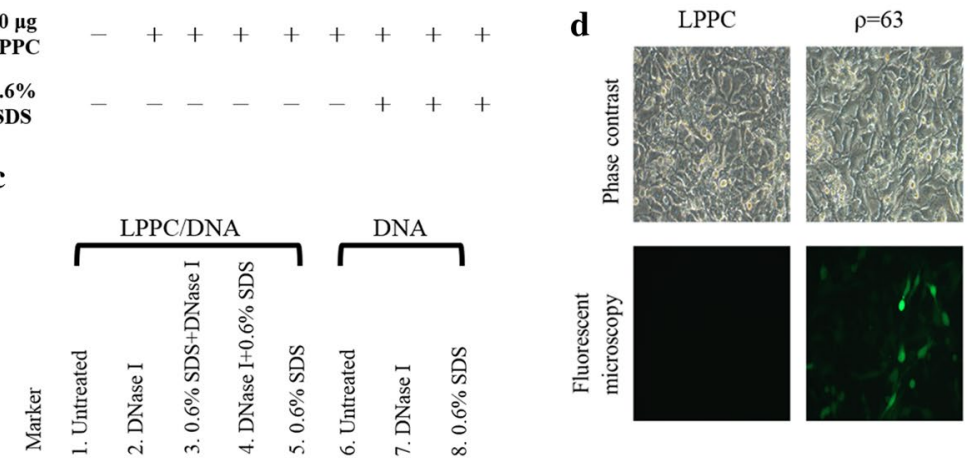

$\rho=21$

$\rho=13$
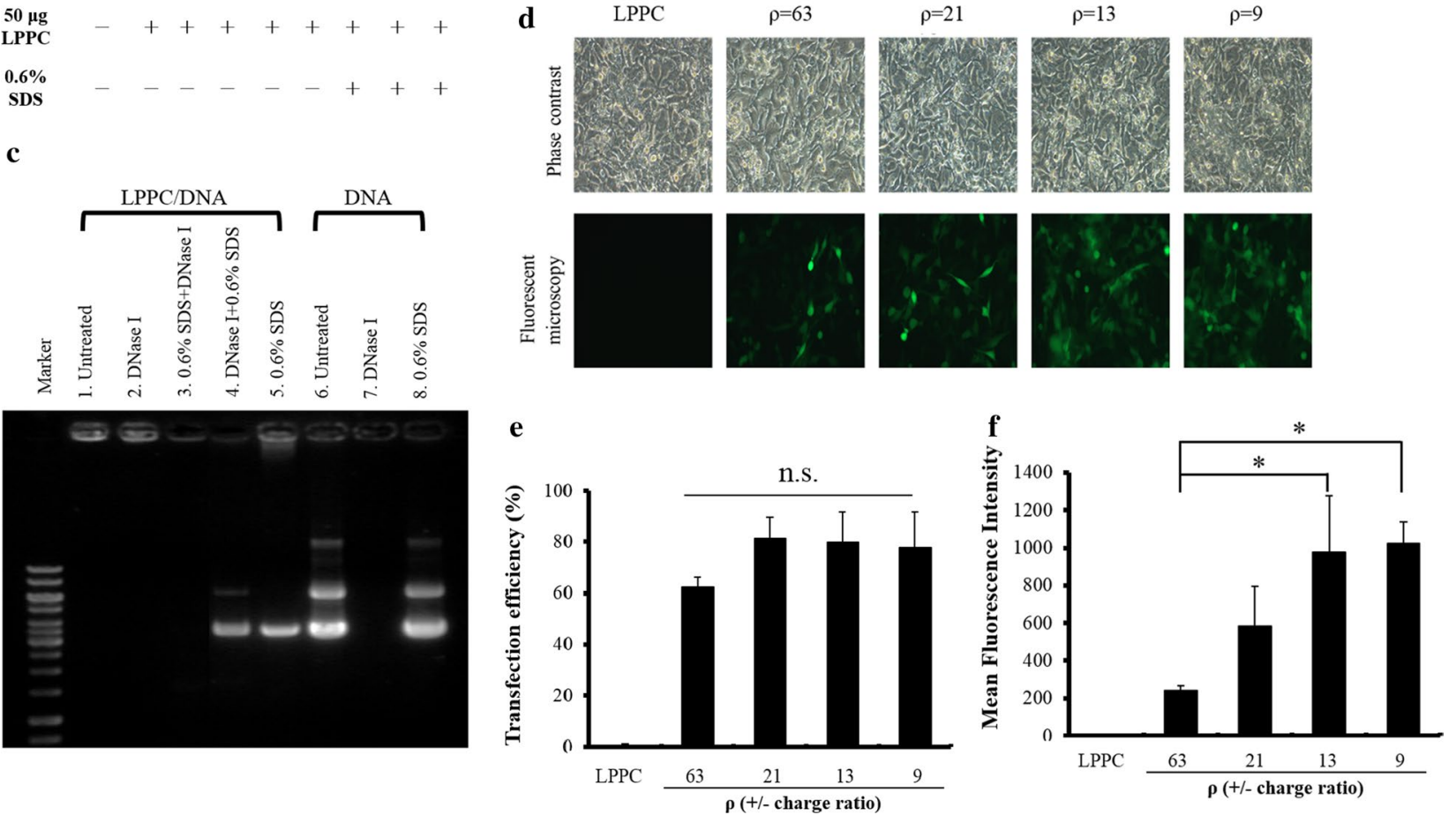

Fig. 1 Characteristics of the LPPC/DNA complexes a LPPC $(50 \mu \mathrm{g})$ was incubated with different amounts of DNA for 30 min at room temperature, and the complexes were determined by 0.8\% agarose electrophoresis. Lane 1 was $5 \mu \mathrm{g}$ DNA alone and lanes 2-5 were 1, 5, 10, and 15 $\mu \mathrm{g}$ DNA with LPPC, respectively. The replacement of DNA from the complexes by competition with $0.6 \%$ SDS is shown in lanes 6-9. $\mathbf{b}$ Different amounts of DNA were incubated with $50 \mathrm{\mu g}$ of LPPC for $30 \mathrm{~min}$ at room temperature, and the amounts of bound DNA were analysed with a spectrophotometric assay. $\mathbf{c}$ The ability of LPPC to protect DNA from DNase I digestion was assessed by treatment with DNase I. Lane 1 was the LPPC/DNA complexes alone; lanes 2-5 were LPPC/DNA complexes treated with DNase I, SDS+ DNase I, DNase I+SDS and SDS alone, respectively; and lanes 6-8 were DNA alone, DNA treated with DNase l, and DNA treated with SDS, respectively. d Different amounts of pAAV-MCS-hrGFP plasmids with $50 \mu \mathrm{g}$ of LPPC at $\rho=63,21,13,9$ ( \pm charge ratio) were transfected into B16-F10 cells, and the cells were observed under a microscope after $48 \mathrm{~h}$. e, $\mathbf{f}$ Flow cytometry was used to analyse the transfection efficacy and the mean fluorescence intensity. The data represent the mean $\pm \operatorname{SD}(n=6)$. Significant differences were evaluated by ANOVA with the Bonferroni test and labelled as $* P<0.05$

In vitro targeting activity of RBDV-IgG1 Fc (RBDV) on LPPC to VEGFR-positive cells

RBDV was used to adsorb on DiO-labelled LPPC to evaluate the specific targeting activity to VEGFR-positive cells
(B16-F10 cells) and VEGFR-negative cells (BALB/3T3 cells). Figure 2a, b show that the DiO-labelled LPPC with or without RBDV or IgG1 Fc (negative control protein) all have a high fluorescence intensity in both cell lines 
Table 1 Average diameters $(\mathrm{nm})$ and zeta potentials $(\mathrm{mV})$ of LPPC complexes (per $50 \mu \mathrm{g}$ of LPPC)

\begin{tabular}{|c|c|c|}
\hline Formulation & Size $(\mathrm{nm})$ & Zeta potential $(\mathrm{mV})$ \\
\hline LPPC & $197 \pm 17.8$ & $4302 \pm 1.4$ \\
\hline $\mathrm{LPPC}+1 \mu \mathrm{g}$ DNA & $263.1 \pm 27.9$ & $37.4 \pm 1.5$ \\
\hline $\mathrm{LPPC}+3 \mu \mathrm{g} D N A$ & $287.7 \pm 29.9$ & $34.9 \pm 2.4$ \\
\hline $\mathrm{LPPC}+5 \mu \mathrm{g} D N A$ & $320.4 \pm 12.4$ & $27.2 \pm 4.8$ \\
\hline $\mathrm{LPPC}+7 \mu \mathrm{g} D N A$ & $365 \pm 22.6$ & $21.7 \pm 3.4$ \\
\hline $\begin{array}{l}\mathrm{LPPC}+5 \mu \mathrm{g} D N A+1 \mathrm{mg} \\
\quad \text { RBDV protein }\end{array}$ & $426.7 \pm 22.7$ & $17.1 \pm 2.3$ \\
\hline $\begin{array}{l}\mathrm{LPPC}+5 \mu \mathrm{g} \text { DNA }+1 \mathrm{mg} \\
\text { RBDV protein + PEG }\end{array}$ & $527.5 \pm 83.4$ & $4.9 \pm 2.0$ \\
\hline
\end{tabular}

The data represent the mean $\pm S D(n=6)$

compared to the untreated cells, which suggests that the cationic character of LPPC causes nonspecific binding of the cells. To improve the specific targeting of the liposomal particles, PEG was used to attenuate the extra cationic charges of the LPPC/protein complex. With PEG complexing, the LPPC/RBDV/PEG complex lost its non-specific binding activity to BALB/3T3 cells but still maintained binding activity to B16-F10 cells; meanwhile, LPPC/PEG and LPPC/IgG1 Fc/PEG also lowered their non-specific binding activities in both cell lines (Fig. 2c, d). Figure 2e shows that the targeting ability of DiO-labelled LPPC to B16-F10 cells by RBDV is dose-dependent.

The abilities of LPPCs to encapsulate different amounts of RBDV or IgG1 Fc proteins for transfection were examined, and the results revealed that the transfectant expressed high fluorescence after treatment with LPPC with different amounts of RBDV in a dose-dependent manner but only showed a low fluorescent signal after treatment with IgG1 Fc (Fig. 3a, b). Flow cytometry also demonstrated that RBDV enhanced the transfection efficiency and the expression of the transfection in a dosedependent manner (Additional file 1: Figure S1).

\section{The effects of the RBDV protein expressed by the transfectant in B16-F10 cells}

Figure 4a shows the expressive abilities of the transfectants after LPPC with RBDV and different plasmids at different times. The VEGFR-positive transfectants significantly expressed RBDV or IgG1 Fc after transfection with pRBDV or pIgG1 Fc. As previously described, VEGFRnegative cells (BALB/3T3 cells) express few or no recombinant proteins at any time after transfection (Fig. 4a). Then, the recombinant proteins in the culture supernatants were examined for their bioactivities. Figure $4 \mathrm{~b}, \mathrm{c}$ show that the pRBDV-expressed RBDV proteins in the B16-F10 transfectants can significantly elicit ADCC and
CDC effects against B16-F10 cells, while the control protein, IgG1 Fc, cannot.

\section{Targeted transfection ability of the LPPC/RBDV complexes in vivo}

The IVIS imaging system first examined the in vivo targeting ability of DiO-labelled LPPC to determine the effects of RBDV and IgG1 Fc. The results show that the RBDV/DiO-labelled LPPC complexes can target B16-F10 tumours at $72 \mathrm{~h}$ and do not accumulate in BALB/3T3 cells or other organs (Fig. 5a). Then, the transfection ability of the LPPC/RBDV complexes was assessed by carrying pAsRed2-N1 to observe the expression of red fluorescent proteins in vivo. Figure $5 \mathrm{~b}$ shows that the reporter gene can be significantly expressed in B16-F10 tumours but not in other organs after 6 days. In addition, the tissue sections also revealed that with RBDV, LPPC/pAsRed2-N1 encoded red fluorescent proteins in B16-F10 tumour tissues but not in other organ tissues. Conversely, the IgG-absorbed LPPC/pAsRed2-N1 lost its ability to be specifically expressed in tumour tissues and caused nonspecific expression in heart, liver, spleen, lung, and kidney tissues (Fig. 5c).

\section{Inhibition of B16-F10 tumour growth by the expressed RBDV protein}

The in vivo expression of LPPC-mediated transgenes was followed by intravenous (i.v.) injection with different formulas, and the sera of the treated mice were collected and measured. Figure 6 indicates that the LPPC/plasmids with either RBDV or IgG1 Fc can transfect the transgene and express the recombinant proteins after i.v. injection for 7 days. Thus, the effects of one i.v. injections with different LPPC complexes on B16-F10 tumour growth were examined. The results show that LPPC-mediated transfections significantly inhibited tumour growth compared with PBS-treated groups over 17 days. The order of the inhibitory efficacy for the treatments was LPPC/pRBDV/ $\mathrm{RBDV}>\mathrm{LPPC} / \mathrm{pRBDV} / \mathrm{IgG} 1>\mathrm{LPPC} / \mathrm{RBDV}=\mathrm{LPPC} /$ pIgG1/RBDV (Additional file 1: Figure S2). To further assess the therapeutic effects of LPPCs on B16-F10 tumour growth, mice were i.v. injected twice with distinct LPPC complexes. The results show that only the LPPC/ pRBDV/RBDV treatment dramatically inhibited tumour growth compared with the other groups (Fig. 7a); moreover, treatment with LPPC/pRBDV/RBDV significantly improved the survival time compared with the other groups (Fig. 7b). Furthermore, the therapeutic effects of LPPC/pRBDV/RBDV were compared with the effects of recombinant RBDV proteins after multiple injections. After four treatments, LPPC/pRBDV/RBDV had better tumour growth inhibition than the recombinant RBDV protein alone (Fig. 8). 


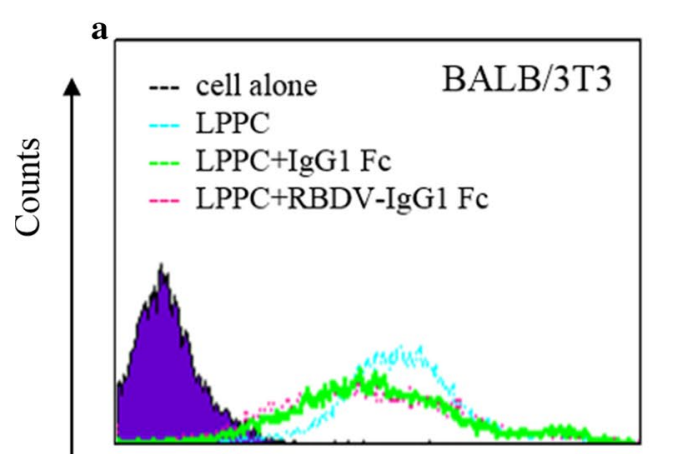

b

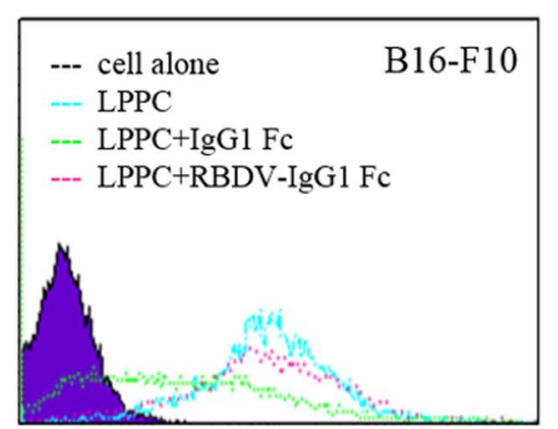

c

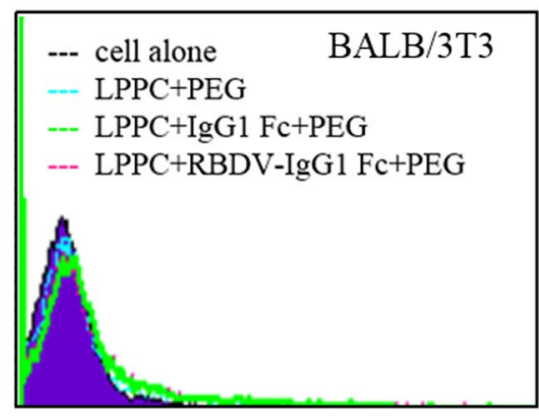

d

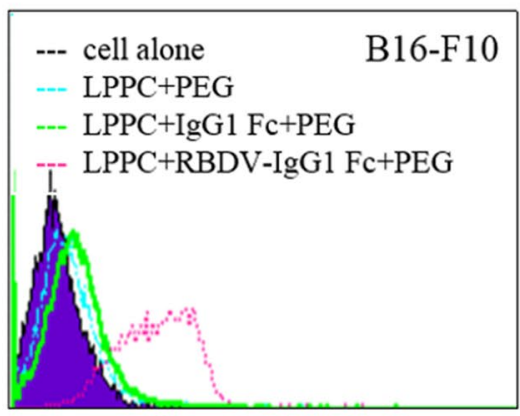

FL1-H

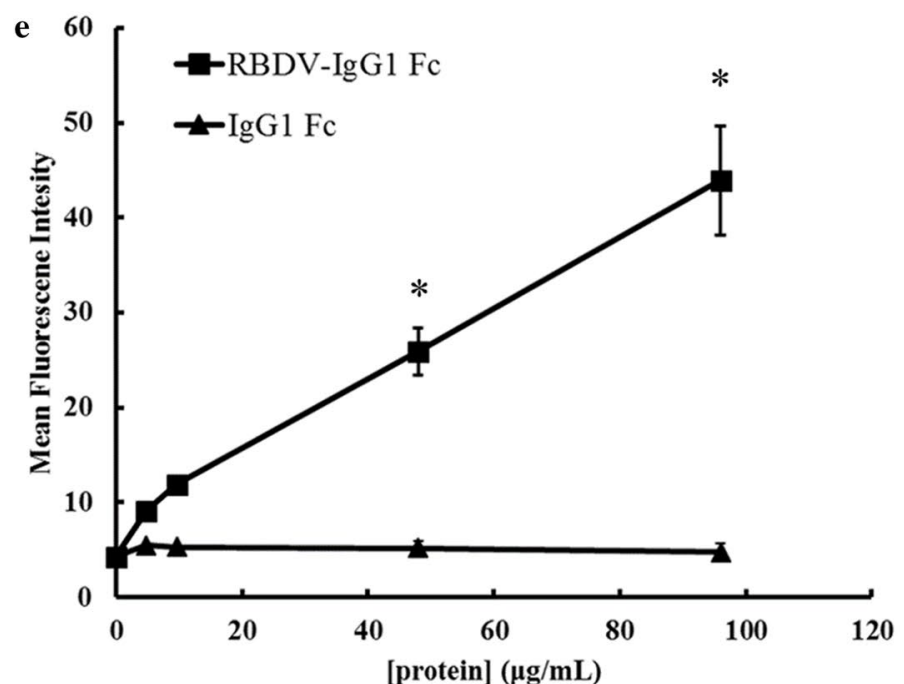

Fig. 2 The binding activities of the LPPC/DiO/RBDV-IgG1 Fc complexes. a BALB/3T3 cells and b B16-F10 cells were stained with DiO-labelled LPPC complexes without PEG 1.500 complexed. c BALB/3T3 cells and d B16-F10 cells were stained with PEG-complexed LPPC/DiO complexes. e DiO-labelled LPPC complexes $(50 \mu \mathrm{g})$ were incubated with different amounts of RBDV-lgG1 Fc or lgG1 Fc proteins for 30 min, and then the complexes were added to B16-F10 cells. The binding intensity was analysed by flow cytometry. The data represent the $\operatorname{mean} \pm \operatorname{SD}(n=6)$. Significant differences are evaluated by Student's $t$-test and are labelled as ${ }^{*} \mathrm{P}<0.05$

\section{Discussion}

In this study, LPPC showed excellent gene transfection capability both in vitro (Fig. 1d) and in vivo (Fig. 5b, c). In combination with targeting molecules, LPPC has been shown to be a specific delivery vector for an antitumour drugs to tumour cells [36]. The targeting molecule RBDV-IgG1 Fc (RBDV) further causes specific gene transfection in vitro (Fig. 3 ) and in vivo (Fig. 5b, 


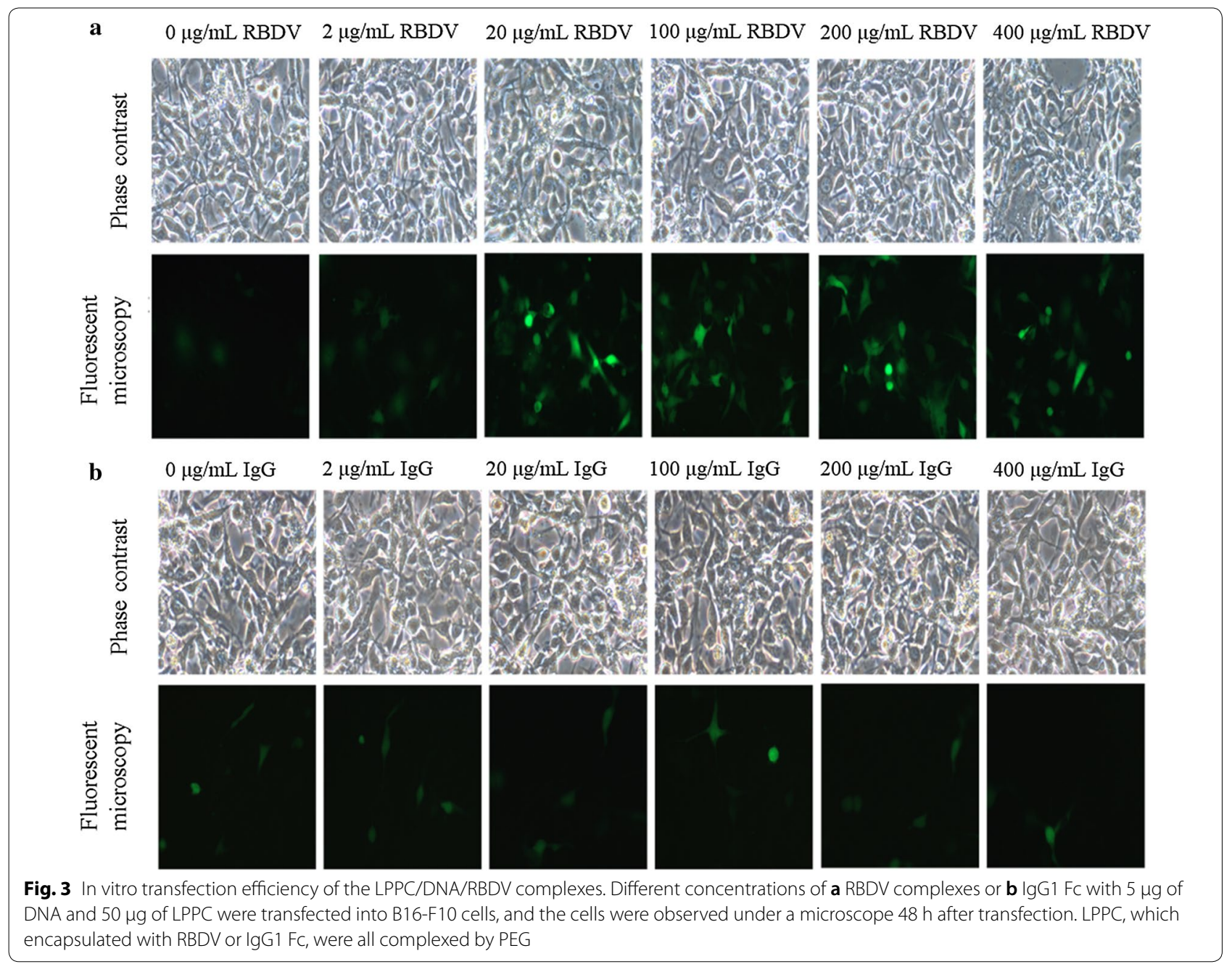

c), which all make LPPC a novel vector in gene therapy. On the other hand, pRBDV also shows benefits of gene therapy on antitumour effects by expressing a therapeutic molecule in vivo (Figs. 5b, c and Additional file 1: Figure S2) through the mechanisms of ADCC and CDC in vitro (Fig. 4b, c). Moreover, we have also confirmed that RBDV protein-directed gene therapy of pRBDV can dramatically suppress tumour progression in mouse melanoma in vivo and provides a better therapeutic efficacy than the administration of pure RBDV protein (Fig. 8) in addition to being a target molecule.

It is an original strategy to use a therapeutic gene that expresses the same therapeutic protein as the targeting molecule (RBDV) at the same time. Currently, researchers have designed a strategy for specific targeted gene therapy using a therapeutic transgene expressing a therapeutic protein that is different from the targeting molecule. For example, scholars have used a PEI-PEG copolymer to covalently link to the
anti-HER2 antibody for the enhancement of truncated-Bid (tBid) killer gene expression, which causes the death of HER2-positive breast cancer cells [37]. Likewise, Huang et al. constructed an immunoliposome-loaded endoglin single-chain antibody for enhancing the expression of the porcine $\alpha 1,3 \mathrm{GT}$ gene to suppress lung cancer [29]. Additionally, Nusrat Khan and his co-workers developed a CD33 targeting vector to express an inducible caspase- 9 suicide gene in acute myeloid leukaemia therapy [38]. None of the current studies of nanoparticle technology in cancer therapy have had the same idea as this study does, and this strategy indeed provides a better therapy than protein-targeted therapy.

In addition, using LPPC as a transfection reagent in this strategy also provides several advantages for specific gene therapy. First, the positive charge of PEI can bind DNA electrostatically and protect the binding DNA from DNase degradation (Fig. 1c). Second, LPPC can stably 
Fig. 4 The expression of the RBDV protein and the in vitro cytotoxicity assay. a pRBDV or plgG1 Fc were transfected into B16-F10 cells and BALB/3T3 cells. The black or white circles mean transfections of LPPC/pRBDV/RBDV/PEG or LPPC/plgG1 Fc/RBDV/PEG in B16-F10 cells, respectively. The black or white squares mean transfections of LPPC/pRBDV/RBDV/PEG or LPPC/plgG1 Fc/RBDV/PEG in BALB/3T3 cells, respectively. The cell culture media were analysed at $0,6,12$, 24, and $48 \mathrm{~h}$ for the amount of protein expression by ELISA. LPPC, which encapsulated with RBDV, were all complexed by PEG. The data represent the mean $\pm S D(n=3)$. Significant differences were evaluated by ANOVA with the Games-Howell test and labelled as *P $<0.05$. b NK-92Ml cells (effector cells) mixed with B16-F10 cells (target cells) at an $E / T$ ratio of 1:1 were co-incubated with IgG1 Fc, RBDV-lgG1 Fc, or VEGF plus RBDV-lgG1 Fc for $5 \mathrm{~h}$, and the cytotoxic activity was determined by MTT assay. The data represent the mean $\pm S D(n=6)$. Significant differences were evaluated by ANOVA with the Bonferroni test and labelled as ${ }^{*} \mathrm{P}<0.05$ compared with other groups. c Complement mixed with B16-F10 cells was co-incubated with $\lg G 1 \mathrm{Fc}$ or RBDV-lgG1 Fc, and the cytotoxic activity was determined by MTT assay. The data represent the mean \pm SD $(n=4)$. Significant differences were evaluated by ANOVA with the Bonferroni test and labelled as ${ }^{*} \mathrm{P}<0.05$ compared with other groups

adsorb proteins via a noncovalent linkage, which retains the flexibility to encapsulate different targeted proteins without damaging the activity of the targeting molecules. Although the covalent linkage of the target molecules to liposomes is a prevalent method for conjugation, this process may attenuate the activities of specific targeting molecules $[39,40]$. Third, LPPC can be centrifuged to form a pellet, which allows LPPC to be easily separated from the unincorporated molecules to avoid the interference of free proteins prepare for use.

Interestingly, although previous studies have shown that RBDV can provide a good anti-angiogenesis effect against tumour growth by targeting both VEGFR1 and VEGFR2, the ability to cause tumour regression by RBDV protein treatment is less useful than pRBDV in this study. Moreover, LPPC with both RBDV and pRBDV revealed the best therapeutic effects among all groups (Fig. 8). There are two possibilities that could explain such a phenomenon. First, RBDV can specifically bind to VEGFR1 and VEGFR2, which leads the LPPC complex to the tumour site and transfects pRBDV. Then, the newly encoded RBDV proteins will have a relatively

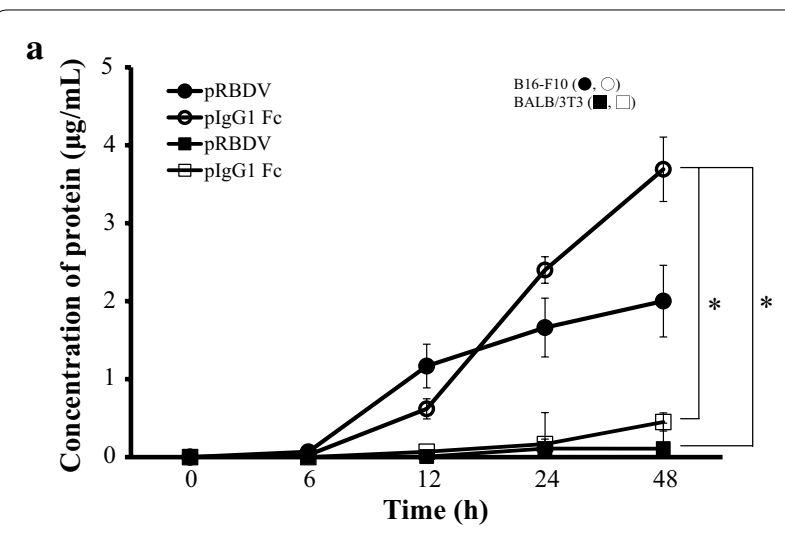

b

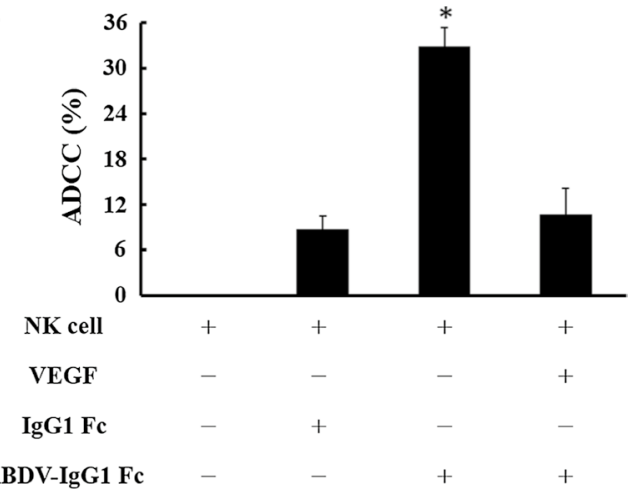

c

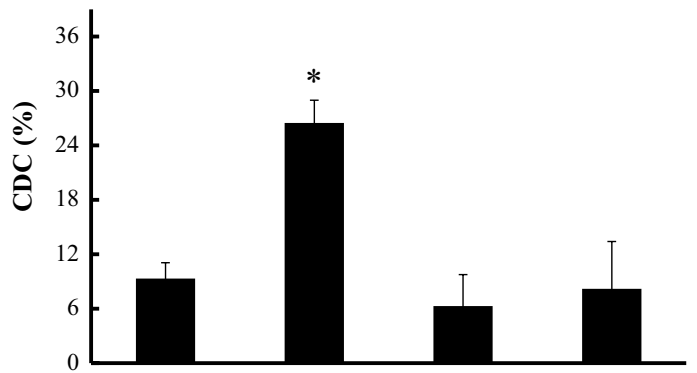

RBDV-IgG1 Fc $\quad+$

$\begin{array}{lllll}\operatorname{IgGl~Fc} & - & - & + & + \\ \begin{array}{llll}\text { Inactive } \\ \text { complement }\end{array} & + & - & + & - \\ \begin{array}{c}\text { Active } \\ \text { complement }\end{array} & - & + & - & +\end{array}$

(See figure on next page.)

Fig. 5 Targeting ability and Targeted transfection ability of the LPPC/RBDV complexes in vivo. a Tumour-bearing mice were i.v. injected with LPPC/ $\mathrm{DiO} / \mathrm{RBDV}$ or LPPC/DiO/IgG1 Fc. After $72 \mathrm{~h}$, the organs and tumours were excised and imaged with an IVIS system at the appropriate wavelength (Em: $600 \mathrm{~nm}$ and Ex: $465 \mathrm{~nm}$ ). b Tumour-bearing mice were i.v. injected with LPPC/pAsRed/RBDV or LPPC/pAsRed/lgG1 Fc. After 6 days, the organs and tumours were excised and imaged with an IVIS system at the appropriate wavelength (Em: $560 \mathrm{~nm}$ and Ex: $465 \mathrm{~nm}$ ). c The tumours and organs were further processed by H\&E staining and photographed with a fluorescence microscope. LPPC, which encapsulated with RBDV or IgG1 FC, were all complexed by PEG 
a

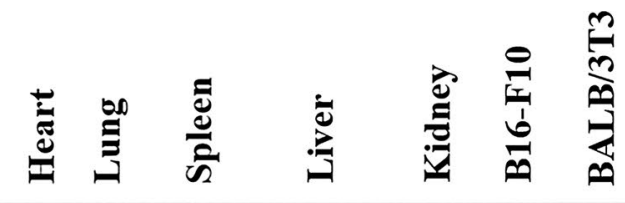

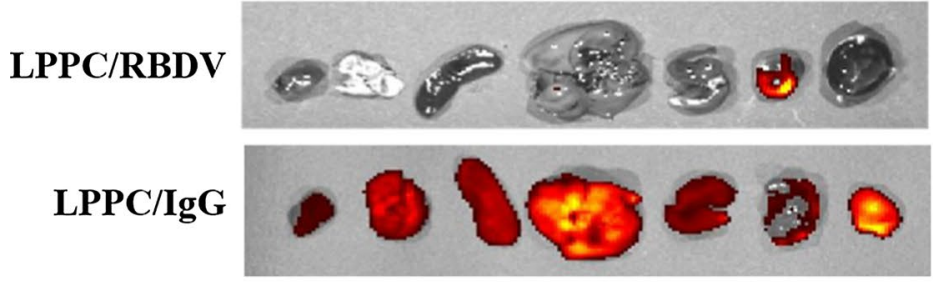

b
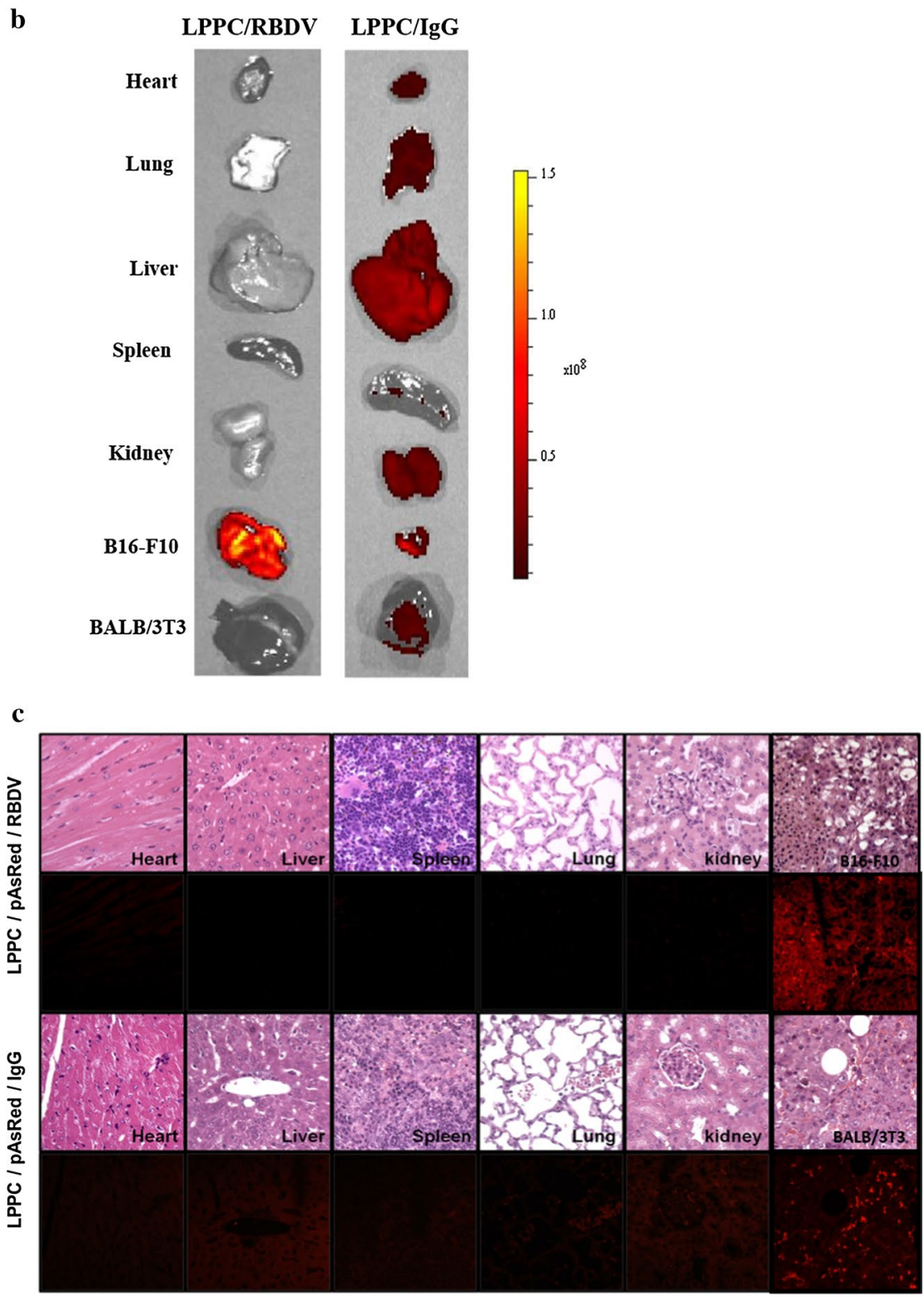


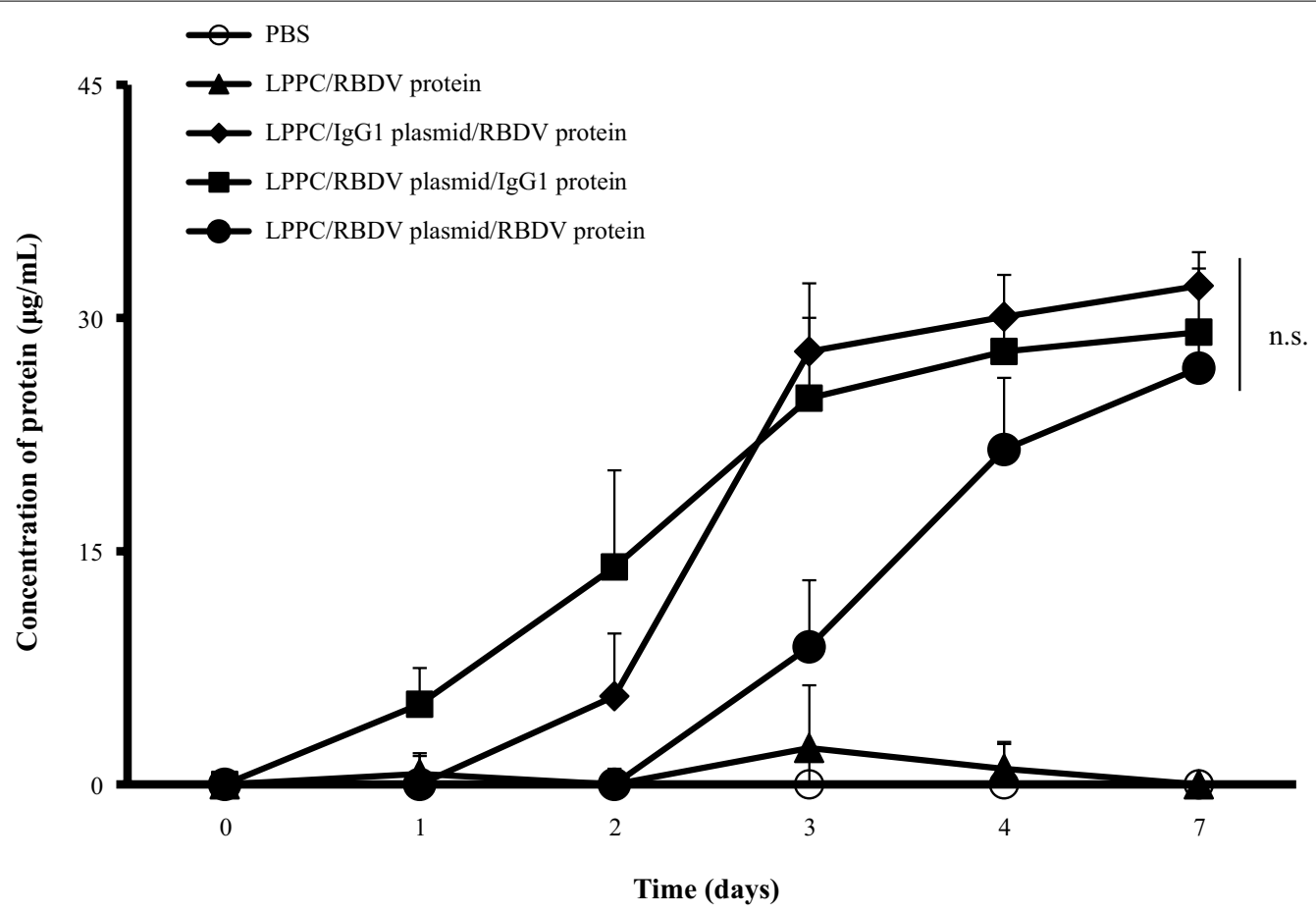

Fig. 6 In vivo expression of RBDV or lgG1 Fc. The LPPC/RBDV-lgG1 Fc protein complexes, LPPC/lgG1 Fc plasmid/RBDV-lgG1 Fc protein complexes, LPPC/RBDV-lgG1 Fc plasmid/lgG1 Fc protein complexes, LPPC/RBDV-lgG1 Fc plasmid/RBDV-lgG1 Fc protein complexes and PBS were i.v. injected into mice. Mouse sera were collected at different times post-administration and analysed by ELISA. LPPC, which encapsulated with RBDV or IgG1 FC, were all complexed by PEG. The data represent the mean $\pm S D(n=3)$. Significant differences were evaluated by ANOVA with the Bonferroni test

higher concentration in the tumour microenvironment than that in other tissues, which contributes to the antitumour effects. Second, the pRBDV transfectant can continue expressing RBDV over time, which makes it a better therapeutic than RBDV.

\section{Conclusions}

In conclusion, we show that LPPC could adsorb not only plasmid DNA and the RBDV protein but also retain their bioactivities. The LPPC/RBDV complexes could target B16-F10 tumours, and the reporter gene pAsRed2-N1 could be significantly expressed in B16-F10 tumours but not on other organs. Modification of cationic liposomes through the addition of specific targeting molecules may make it possible to increase uptake by angiogenetic endothelial cells and decrease uptake by healthy endothelial cells and macrophages. Hence, the concept of using LPPC-encapsulated PRBDV and the RBDV protein might be a useful strategy for specific gene delivery.

\section{Methods}

\section{Cell lines, animals and reagents}

Human embryonic kidney (HEK) 293T cells, mouse melanoma B16-F10 cells, and mouse embryonic fibroblast BALB/3T3 cells were obtained from the Bioresource
Collection and Research Center (BCRC, Hsinchu City, Taiwan, ROC). These cells were cultured in Dulbecco's modified Eagle's medium (DMEM; Invitrogen, Gaithersburg, MD, USA) supplemented with inactivated $10 \%$ foetal bovine serum (FBS; Invitrogen) and 1\% penicillinstreptomycin amphotericin B (PSA; Biological industries, New York, NY, USA). Human natural killer NK-92 MI cells were grown in alpha minimum essential medium ( $\alpha$ MEM; Sigma-Aldrich, St. Louis, MO, USA) supplemented with $0.2 \mathrm{mM}$ inositol (Sigma-Aldrich), $0.2 \mathrm{mM}$ 2-mercaptoethanol (Sigma-Aldrich), $0.02 \mathrm{mM}$ folic acid (Sigma-Aldrich), 12.5\% horse serum (Gibco BRL, Gaithersburg, MD, USA) and $12.5 \%$ FBS. All cells were incubated at $37{ }^{\circ} \mathrm{C}$ in an atmosphere of $5 \% \mathrm{CO}_{2}$.

Male C57BL/6 mice (6-8 weeks old) were purchased from the National Laboratory Animal Center (NLAC, Taipei City, Taiwan, ROC).

1,2-Dioleoyl-sn-glycero-3-phosphocholine (DOPC) (Avanti Polar Lipids, Inc., Alabaster, AL, USA), 1,2-dilauroyl-sn-glycero-3-phosphocholine (DLPC) (Avanti Polar Lipids, Inc.) and polyethylene glycol (PEG, MW 1.500) (Shimo-Meguro, Meguro-Ku, Tokyo, Japan), PEG (MW 8.000, Sigma-Aldrich) and polyethylenimine (PEI, branched, MW 25.000, SigmaAldrich) were purchased to prepare LPPC. 

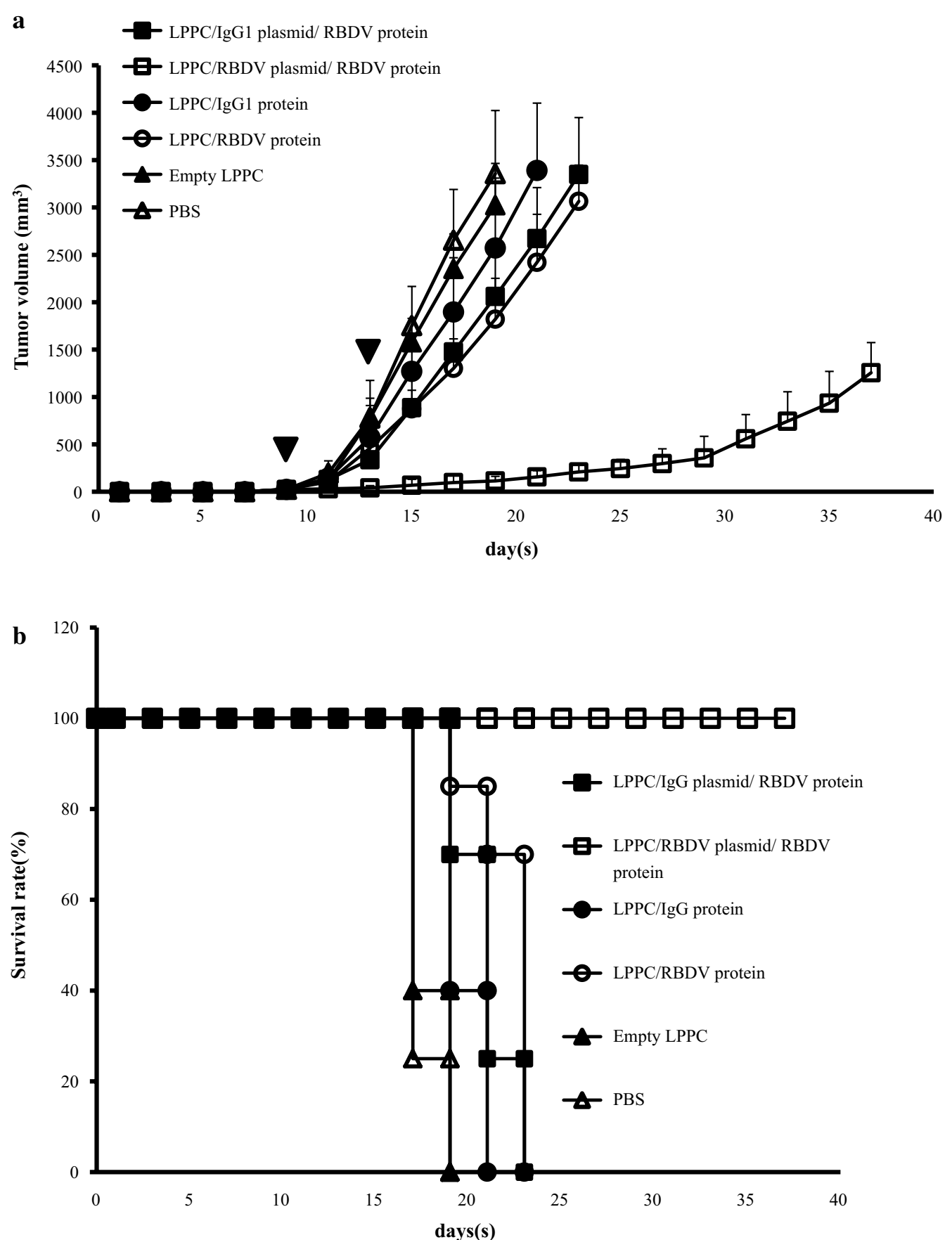

Fig. 7 Inhibition of tumour growth by the LPPC/RBDV-lgG1 Fc plasmid/RBDV-lgG1 Fc protein. a Female C57BL/6 mice (6-8 weeks of age) were subcutaneously inoculated with $1 \times 10^{6}$ cells in $100 \mathrm{~mL}$ of PBS. When the average tumour volume reached $30 \mathrm{~mm}^{3}$, the mice were i.v. injected with LPPC/RBDV-IgG1 Fc plasmid/RBDV-IgG1 Fc protein or other groups and injected again after four days. Inverted filled triangle means the day of complex injection. Tumour volume was measured every 2 days after injecting the complexes, and the mice were sacrificed when the tumour grew to a size of $2500 \mathrm{~mm}^{3}$. The data represent the mean tumour volume $\pm S D(n=7)$. b The survival rate of C57BL/6 mice bearing B16-F10 tumours treated with LPPC/RBDV-lgG1 Fc plasmid/RBDV-lgG1 Fc protein or other groups. LPPC, which encapsulated with RBDV or lgG1 Fc, were all complexed by PEG 


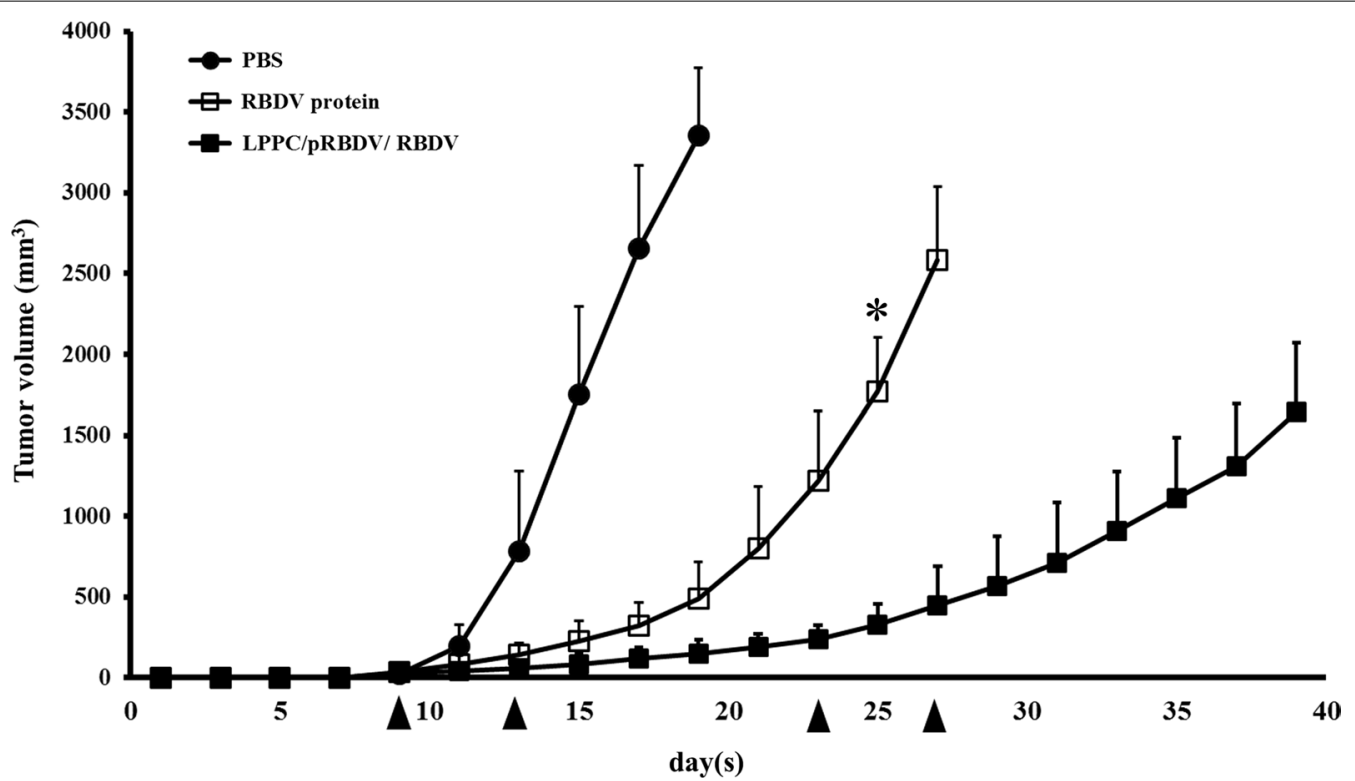

Fig. 8 Inhibition of tumour growth by LPPC/pRBDV/RBDV and the RBDV protein. Female C57BL/6 mice (6-8 weeks of age) were subcutaneously inoculated with $1 \times 10^{6}$ cells in $100 \mathrm{~mL}$ of PBS. When the average tumour volume reached $30 \mathrm{~mm}^{3}$, the mice were i.v. injected with LPPC/pRBDV/ RBDV or RBDV protein. Inverted filled triangle means the day of complex injection. Tumour volume was measured every 2 days after injection of the complexes, and the mice were sacrificed when the tumour grew to a size of $2500 \mathrm{~mm}^{3}$. LPPC, which encapsulated with RBDV or lgG1 Fc, were all complexed by PEG. The data represent the mean $\pm S D(n=7)$. Significant differences are evaluated by Student's $t$-test and are labelled as $* P<0.05$

\section{Plasmid construction}

The pAAV-MCS-hrGFP plasmid was cloned from pNFkB-hrGFP and pAAV-MCS (Stratagene, La Jolla, CA, USA). The pAsRed2-N1 plasmid was purchased from BD Biosciences (San Jose, CA, USA). Plasmids pAAV-MCS/ RBDV-IgG1 and pAAV-MCS/IgG1 were constructed according to the procedures in previous studies [33, 41]. All plasmids were amplified and purified with the GeneSpin MidiPrep Kit (Protech Technology, Taipei City, Taiwan, ROC).

\section{Preparation of the RBDV-lgG1 Fc (RBDV) and IgG1 Fc recombinant proteins}

RBDV and IgG1 Fc recombinant fusion proteins were produced and purified according to the procedures in previous studies $[33,41]$. Briefly, the two plasmids were transfected into 293T cells. After $48 \mathrm{~h}$, the supernatants of the cell culture media were collected and purified by Protein G-Agarose (Upstate, Inc., Lake Placid, NY, USA). Then, the eluted fractions were further purified by a nickel-charged HisTrap Hp affinity column (Amersham Biosciences, Piscataway, NJ, USA). Finally, the solvents of the eluted proteins were exchanged in PBS by a Sephadex G-25 prepacked column (Amersham Biosciences), and the recombinant fusion proteins were concentrated with Microcon Centrifugal Filters (Millipore, Bedford, MA, USA). The concentrations of the RBDV and IgG1
Fc recombinant fusion proteins were calculated by the Bradford assay by measuring the absorbance at $595 \mathrm{~nm}$ with a Sunrise ${ }^{\mathrm{TM}}$ absorbance microplate reader (TECAN, Männedorf, Zurich, Switzerland).

\section{Preparation of the LPPC and LPPC/DNA complexes}

LPPC was produced according to the procedures in a previous study [34]. In brief, LPPC was prepared with two kinds of lipids (DOPC and DLPC) and two kinds of polymers (PEG and PEI). The molar ratio of lipids:PEI:PEG was approximately 13:5:5.

The amounts of DNA complexed to LPPC were based on the nitrogen/phosphate ratio $(\rho)$, which refers to the molar ratio of amine and phosphate groups in PEI of LPPC and DNA, respectively. For LPPC/DNA complex preparation, $5 \mu \mathrm{L}$ of LPPC $(50 \mu \mathrm{g} / \mathrm{mL})$ was mixed with 1 , $3,5,7 \mu \mathrm{g}$ of hrGFP plasmids at $25^{\circ} \mathrm{C}$ for $30 \mathrm{~min}$ to give a final volume of $15 \mu \mathrm{L}$ LPPC/DNA complexes at $\rho=63$, $21,13,9$, respectively.

For LPPC/DNA/RBDV complex preparation, $5 \mu \mathrm{L}$ of LPPC $(50 \mu \mathrm{g} / \mathrm{mL})$ was mixed with $5 \mu \mathrm{g}$ hrGFP plasmid at $25{ }^{\circ} \mathrm{C}$ for $30 \mathrm{~min}$, and then different amounts of RBDV were added for another $30 \mathrm{~min}$ to a final volume of $50 \mu \mathrm{L}$ LPPC/DNA/RBDV complexes. Finally, the extra positive charges of the complexes were attenuated with $50 \mu \mathrm{L}$ of PEG $1.500(100 \mathrm{mg} / \mathrm{mL})$ for $30 \mathrm{~min}$ twice. 


\section{Gel retardation assay}

The binding of LPPC to the hrGFP plasmid with or without $0.6 \%$ SDS was assayed by gel retardation analysis. Different amounts of plasmids and $0.6 \%$ SDS were added to $50 \mu \mathrm{g}$ of LPPC and briefly shaken. After $30 \mathrm{~min}$ of incubation at room temperature, $10 \mu \mathrm{L}$ of the LPPC/DNA complexes were analysed by agarose gel electrophoresis. DNA was visualized with a UV lamp by using a Uni-photo gel image system (EZ lab, Keelung City, Taiwan, ROC).

\section{Size and zeta potential measurements}

Ten microliters of the LPPC/DNA complexes were prepared as described above. The particle size and zeta potential were determined with a BI-200SM dynamic laser light scattering goniometer (Brookhaven, Inc., Holtsville, NY, USA).

\section{In vitro transfection}

To study the transfection activity of the different LPPC/ DNA complexes and LPPC/DNA/RBDV complexes, B16-F10 cells were seeded in 6-well plates at $2 \times 10^{5}$ cells per well in $3 \mathrm{~mL}$ of DMEM containing 10\% FBS and 1\% PSA. The cell lines were incubated at $37{ }^{\circ} \mathrm{C}$ overnight in $5 \% \mathrm{CO}_{2}$, and then the media was replaced with $1 \mathrm{~mL}$ of serum-free DMEM containing different LPPC complexes for $6 \mathrm{~h}$ at $37^{\circ} \mathrm{C}$. After $6 \mathrm{~h}, 2 \mathrm{~mL}$ of fresh DMEM growth media was added to the cells and followed by incubation for an additional $42 \mathrm{~h}$. Then, the cells were resuspended in trypsin, and the transfection efficiency was measured by using FACScan flow cytometry (BD Biosciences).

\section{Antibody-dependent cell-mediated cytotoxicity (ADCC) and complement-dependent cytotoxicity (CDC) assay}

The ADCC is typically triggered by immune cells such as NK cells, which can recognize the Fc region of IgG and induce the IgG-targeted cell to apoptosis. Besides, the $\mathrm{CDC}$ assay, which is triggered by the binding of C1q protein to the IgG can cause the IgG-targeted cell lysis by the activation of complement. Hence, the ADCC and CDC assays were used to verify the effects of RBDV at B16-F10 cells in presence of immunity in vitro.

Briefly, after $48 \mathrm{~h}$ of LPPC transfection, the supernatants of the cell culture media with the RBDV or IgG1 protein were collected for the analysis of ADCC and CDC assays.

In the ADCC assay, B16-F10 cells (target cells) were seeded in 96-well plates at $1 \times 10^{4}$ cells per well overnight. Then, $2 \mu \mathrm{g}$ of RBDV or IgG1 protein was added to the cells for $2 \mathrm{~h}, 1 \mu \mathrm{g} / \mathrm{mL}$ VEGF was added for $20 \mathrm{~min}$, and the cells were treated with $2 \mu \mathrm{g}$ of RBDV for another $1 \mathrm{~h}$. NK-92 MI cells (effector cells) were also added to the plates at $1 \times 10^{4}$ cells/well in $100 \mu \mathrm{L}$ of $\alpha \mathrm{MEM}$ for $4 \mathrm{~h}$. Finally, the culture media was replaced by the working concentration of MTT (Sigma-Aldrich) for $4 \mathrm{~h}$. The supernatants of the cell culture media were removed, and $100 \mu \mathrm{L}$ of dimethyl sulfoxide (DMSO) was added to solubilize the MTT crystals. The ADCC effects on cell proliferation were determined by measuring the absorbance at $595 \mathrm{~nm}$ with a Sunrise ${ }^{\mathrm{TM}}$ absorbance microplate reader (TECAN).

In the CDC assay, B16-F10 cells were coated in a 96-well flat-bottom plate at $1 \times 10^{4}$ cells per well. Two micrograms of RBDV or IgG1 protein was added to each well, and the cells were incubated for $2 \mathrm{~h}$. Then, $200 \mu \mathrm{L}$ of horse serum (Gibco BRL) as a source of active complement was added to each well for $2 \mathrm{~h}$. Then, the supernatants of each well were removed and supplemented with MTT reagent for the cell proliferation assay.

\section{Quantification of the expressed RBDV and IgG1 Fc recombinant proteins}

Plates were coated with $100 \mu \mathrm{L} /$ well anti-human IgG antibody (250 ng) overnight at room temperature, followed by a blocking procedure with $2 \%$ skim milk in PBS for $1 \mathrm{~h}$. RBDV and IgG1 Fc proteins ranging from 0 to $50 \mu \mathrm{g} / \mathrm{mL}$ were used to establish standard curves, and the supernatants from the in vitro transfection cell media or mouse sera were added. The standard ELISA protocol followed, and the absorbance was measured at $450 \mathrm{~nm}$ with a Sunrise absorbance microplate reader (TECAN).

\section{In vivo imaging}

The tumour-targeting effects of RBDV were investigated with a Caliper IVIS Spectrum system (Caliper Life Sciences, Hopkinton, MA, USA), and the in vivo distribution of LPPC-modified complexes in C57BL/6 mice was observed. Briefly, B16-F10 or BALB/3T3 cells $\left(1 \times 10^{5}\right)$ were implanted subcutaneously into the backs of mice. When the tumour size reached $50 \mathrm{~mm}^{3}$, two groups of mice were given either $\mathrm{LPPC} / \mathrm{DiO} / \mathrm{RBDV}$ or $\mathrm{LPPC} / \mathrm{DiO} /$ IgG1 Fc in the amounts of $80 \mu \mathrm{g}$ of RBDV, $80 \mu \mathrm{g}$ of IgG1 Fc and $4 \mathrm{mg}$ of LPPC via tail vein injection. At 0,48 , and $72 \mathrm{~h}$ post-injection, the mice were observed in the IVIS system with an appropriate wavelength of Em: $600 \mathrm{~nm}$ and Ex: $465 \mathrm{~nm}$. Then, the mice were sacrificed, and the organs were imaged.

In another experiment, LPPC/pAsRed2N1/RBDV complexes were injected via the tail vein. At 6 days post-injection, the mice were sacrificed, and then the organs and tumours were excised and imaged with wavelengths Em: $560 \mathrm{~nm}$ and Ex: $465 \mathrm{~nm}$.

\section{Therapeutic experiment}

B16-F10 cells $\left(1 \times 10^{5}\right)$ were implanted subcutaneously into the backs of mice. When the average tumour volumes reached $30 \mathrm{~mm}^{3}$, which occurred within 
7 days post-implantation, the mice were injected intravenously with RBDV/pRBDV/LPPC complexes $(80 \mu \mathrm{g} / 400 \mu \mathrm{g} / 4 \mathrm{mg})$. The tumour volumes were measured every 2 days. Once the tumour volume reached $2500 \mathrm{~mm}^{3}$, the euthanasia procedures of mice were performed under the standard protocol. The tumours and organs of the mice were excised, fixed with paraformaldehyde, and examined by microscopic haematoxylin and eosin (H\&E) staining.

\section{H\&E staining}

The tumours and organs of the mice were embedded in paraffin wax after dehydration. Then, the tissue sections ( $4 \mu \mathrm{m} /$ section) from paraffin-embedded blocks were collected on clean glass slides and dehydrated for $30 \mathrm{~min}$ at $60{ }^{\circ} \mathrm{C}$. The tissue slides were further deparaffinized, rehydrated, and stained with Mayer's haematoxylin and eosin Y solution for $3 \mathrm{~min}$. Finally, the tissue slides were mounted with mounting media and photographed by microscopy.

\section{Statistical analysis}

The data represent the mean \pm standard deviation (SD) of two or three independent experiments. Statistical analysis was performed by Student's $t$-test or analysis of variance (ANOVA) with Bonferroni or Games-Howell test and were calculated with IBM SPSS software (IBM Corp., Armonk, NY, USA). The significant differences are labelled with *for $\mathrm{P}<0.05$.

\section{Supplementary information}

Supplementary information accompanies this paper at https://doi. org/10.1186/s12951-020-00610-9.

Additional file 1: Figure S1. In vitro transfection ability of the LPPC/DNA/ RBDV complexes. Different concentrations of RBDV were encapsulated by LPPC/DNA, which was transfected into B16-F10 cells, and the cells were analysed for (A) the transfection efficiency and (B) the mean fluorescence intensity by flow cytometry. LPPC, which encapsulated with RBDV, were all complexed by PEG. The data represent the mean \pm SD $(n=2)$. Figure S2. In vivo the effects on tumour growth inhibition of RBDV or lgG1 Fc. Female C57BL/6 mice (6-8 weeks of age) were subcutaneously inoculated with $1 \times 10^{6}$ cells in $100 \mathrm{~mL}$ of PBS. When the average tumour volume reached $30 \mathrm{~mm}^{3}$, the mice were intravenously (i.v.) injected with LPPC/ RBDV-lgG1 Fc plasmid /RBDV-lgG1 Fc protein or other groups. $\nabla$ Means the day of complex injection. $(n=3)$. LPPC, which encapsulated with RBDV or lgG1 Fc, were all complexed by PEG.

\section{Acknowledgements}

Not applicable.

\section{Authors' contributions}

$\mathrm{CHC}$ and SYH performed the in vitro studies. SYH, PRC, and KWL wrote the manuscript. NMT and XFH made the tissue sections and performed the histological analysis. YLC and CHC performed the biodistribution of LPPC and the IVIS images in vivo. YHL, CSL, CHC performed tumour therapy studies. CHC, PRC, and YKL supported the manufacture of LPPC. SLW and KWL designed all the experiments in this study. All authors have read and approved the final manuscript.

\section{Funding}

This work was financially supported by the "Center for Intelligent Drug Systems and Smart Biodevices (IDS2B)" from The Featured Areas Research Center Program within the framework of the Higher Education Sprout Project by the Ministry of Education (MOE) in Taiwan, ROC and the Hsinchu MacKay Memorial Hospital (MMH-HB-10802 and MMH-CT-10805) in Taiwan, ROC.

\section{Availability of data and materials}

The datasets used and/or analysed during the current study are available from the corresponding author upon reasonable request.

\section{Ethics approval and consent to participate}

All animal studies were approved and under the standard procedures by the superintendence of the Institutional Animal Care and Use Committee (IACUC) at National Chiao Tung University (NCTU-IACUC-104034) in Taiwan, ROC.

\section{Consent for publication}

Not applicable.

\section{Competing interests.}

The authors declare that they have no competing interests.

\section{Author details}

${ }^{1}$ Department of Biological Science and Technology, National Chiao Tung University, Hsinchu City 30068, Taiwan, ROC. ${ }^{2}$ Institute of Molecular Medicine and Bioengineering, National Chiao Tung University, Hsinchu City 30068, Taiwan, ROC. ${ }^{3}$ Department of Medical Research, Hsinchu Mackay Memorial Hospital, Hsinchu City 30071, Taiwan, ROC. ${ }^{4}$ Department of Medical Laboratory and Biotechnology, Chung Shan Medical University, Taichung City 40201, Taiwan, ROC. ${ }^{5}$ Department of Pathology and Clinical Laboratory, Chung Shan Medical University Hospital, Taichung City 40201, Taiwan, ROC. ${ }^{6}$ Ph.D. Program in Industrial Development of College of Biological Science and Technology, National Chiao Tung University, Hsinchu City 30068, Taiwan, ROC. ${ }^{7}$ Department of Veterinary Medicine, School of Veterinary Medicine, National Taiwan University, Taipei City 10617, Taiwan, ROC. ${ }^{8}$ Animal Cancer Center, College of Bioresources and Agriculture, National Taiwan University, Taipei City 10617, Taiwan, ROC. ${ }^{9}$ Institute of Medicine of Chung, Shan Medical University, Taichung City 40201, Taiwan, ROC. ${ }^{10}$ Department of Life Science, Chinese Culture University, Taipei City 11114, Taiwan, ROC. ${ }^{11}$ Hank Clinic Orthopedics Surgery, Miaoli County 35157, Taiwan, ROC. ${ }^{12}$ Department of Medicine, MacKay Medical College, New Taipei City 25245, Taiwan, ROC. ${ }^{13}$ Department of Obstetrics and Gynecology, Hsinchu MacKay Memorial Hospital, Hsinchu City 30071, Taiwan, ROC. ${ }^{14}$ Graduate Institute of Medicine, College of Medicine, Kaohsiung Medical University, Kaohsiung City 80708, Taiwan, ROC. ${ }^{15}$ Center for Intelligent Drug Systems and Smart Bio-Devices, National Chiao Tung University, Hsinchu City 30068, Taiwan, ROC.

Received: 24 January 2020 Accepted: 16 March 2020

Published online: 09 April 2020

\section{References}

1. Hanahan D, Folkman J. Patterns and emerging mechanisms of the angiogenic switch during tumorigenesis. Cell. 1996;86:353-64.

2. Kerbel RS. Tumor angiogenesis. N Engl J Med. 2008;358:2039-49.

3. Folkman J, Klagsbrun M. Angiogenic factors. Science. 1987;235:442-7.

4. Ribatti D, Vacca A, Presta M. The discovery of angiogenic factors: a historical review. Gen Pharmacol. 2000;35:227-31.

5. Voss MJ, Niggemann B, Zanker KS, Entschladen F. Tumour reactions to hypoxia. Curr Mol Med. 2010;10:381-6.

6. Semenza GL. Hypoxia, clonal selection, and the role of HIF-1 in tumor progression. Crit Rev Biochem Mol Biol. 2000;35:71-103.

7. Ferrara N. VEGF and the quest for tumour angiogenesis factors. Nat Rev Cancer. 2002;2:795-803.

8. Relf M, LeJeune S, Scott PA, Fox S, Smith K, Leek R, Moghaddam A, Whitehouse R, Bicknell R, Harris AL. Expression of the angiogenic factors vascular endothelial cell growth factor, acidic and basic fibroblast 
growth factor, tumor growth factor beta-1, platelet-derived endothelial cell growth factor, placenta growth factor, and pleiotrophin in human primary breast cancer and its relation to angiogenesis. Cancer Res. 1997;57:963-9.

9. Shibuya M. Vascular Endothelial Growth Factor (VEGF) and Its Receptor (VEGFR) signaling in angiogenesis: a crucial target for anti- and proangiogenic therapies. Genes Cancer. 2011;2:1097-105.

10. Shibuya M. VEGF-receptor inhibitors for anti-angiogenesis. Nihon Yakurigaku Zasshi. 2003;122:498-503.

11. Friedman HS, Prados MD, Wen PY, Mikkelsen T, Schiff D, Abrey LE, Yung WK, Paleologos N, Nicholas MK, Jensen R, et al. Bevacizumab alone and in combination with irinotecan in recurrent glioblastoma. J Clin Oncol. 2009;27:4733-40.

12. Van Cutsem E, Tabernero J, Lakomy R, Prenen H, Prausova J, Macarulla T, Ruff P, van Hazel GA, Moiseyenko V, Ferry D, et al. Addition of aflibercept to fluorouracil, leucovorin, and irinotecan improves survival in a phase III randomized trial in patients with metastatic colorectal cancer previously treated with an oxaliplatin-based regimen. J Clin Oncol. 2012;30:3499-506.

13. Fuchs CS, Tomasek J, Yong CJ, Dumitru F, Passalacqua R, Goswami C, Safran H, Dos Santos LV, Aprile G, Ferry DR, et al. Ramucirumab monotherapy for previously treated advanced gastric or gastro-oesophageal junction adenocarcinoma (REGARD): an international, randomised, multicentre, placebo-controlled, phase 3 trial. Lancet. 2014;383:31-9.

14. Lee SY, Kim DK, Cho JH, Koh JY, Yoon YH. Inhibitory effect of bevacizumab on the angiogenesis and growth of retinoblastoma. Arch Ophthalmol. 2008;126:953-8.

15. Sharma T, Dhingra R, Singh S, Sharma S, Tomar P, Malhotra M, Bhardwaj TR. Aflibercept: a novel VEGF targeted agent to explore the future perspectives of anti-angiogenic therapy for the treatment of multiple tumors. Mini Rev Med Chem. 2013;13:530-40.

16. Spannuth WA, Nick AM, Jennings NB, Armaiz-Pena GN, Mangala LS, Danes CG, Lin YG, Merritt WM, Thaker PH, Kamat AA, et al. Functional significance of VEGFR-2 on ovarian cancer cells. Int J Cancer. 2009;124:1045-53.

17. Qureshi S, Elliott RB, Herrington JD. Concurrent gastrointestinal perforation and pulmonary embolism due to bevacizumab in an adult undergoing treatment for stage IV colon cancer. J Oncol Pharm Pract. 2017;23:625-8.

18. Keramida K, Charalampopoulos G, Filippiadis D, Tsougos E, Farmakis D. Cardiovascular complications of metastatic colorectal cancer treatment. J Gastrointest Oncol. 2019;10:797-806.

19. van der Woude SO, van Laarhoven HW. Acute hypertension during ramucirumab infusion in two patients with advanced oesophagogastric cancer. BMJ Case Rep. 2016. https://doi.org/10.1136/bcr-2016-215801.

20. Cao Y. Endogenous angiogenesis inhibitors and their therapeutic implications. Int J Biochem Cell Biol. 2001;33:357-69.

21. Eskens FA, Verweij J. The clinical toxicity profile of vascular endothelial growth factor (VEGF) and vascular endothelial growth factor receptor (VEGFR) targeting angiogenesis inhibitors; a review. Eur J Cancer. 2006:42:3127-39.

22. Verheul HM, Pinedo HM. Possible molecular mechanisms involved in the toxicity of angiogenesis inhibition. Nat Rev Cancer. 2007;7:475-85.

23. Li T, Kang G, Wang T, Huang H. Tumor angiogenesis and anti-angiogenic gene therapy for cancer. Oncol Lett. 2018;16:687-702.

24. Hardee CL, Arevalo-Soliz LM, Hornstein BD, Zechiedrich L. Advances in non-viral DNA vectors for gene therapy. Genes. 2017;8:65.

25. Nayerossadat N, Maedeh T, Ali PA. Viral and nonviral delivery systems for gene delivery. Adv Biomed Res. 2012;1:27.

26. Wang F, Sun Y, Shi J. Programmed death-ligand 1 monoclonal antibodylinked immunoliposomes for synergistic efficacy of miR-130a and oxaliplatin in gastric cancers. Nanomedicine. 2019;14:1729-44.

27. Alshaer W, Hillaireau H, Vergnaud J, Mura S, Delomenie C, Sauvage F, Ismail S, Fattal E. Aptamer-guided siRNA-loaded nanomedicines for systemic gene silencing in CD-44 expressing murine triple-negative breast cancer model. J Control Release. 2018;271:98-106.

28. Mahmud H, Kasai T, Khayrani AC, Asakura M, Oo AKK, Du J, Vaidyanath A, El-Ghlban S, Mizutani A, Seno A, et al. Targeting glioblastoma cells expressing CD44 with liposomes encapsulating doxorubicin and displaying chlorotoxin-IgG Fc fusion protein. Int J Mol Sci. 2018;19:659.

29. Huang Y, Huang Y, He J, Wang H, Luo Y, Li Y, Liu J, Zhong L, Zhao Y. PEGylated immunoliposome-loaded endoglin single-chain antibody enhances anti-tumor capacity of porcine alpha1,3GT gene. Biomaterials. 2019;217:119231.

30. Fox CB, Sivananthan SJ, Duthie MS, Vergara J, Guderian JA, Moon E, Coblentz D, Reed SG, Carter D. A nanoliposome delivery system to synergistically trigger TLR4 AND TLR7. J Nanobiotechnol. 2014;12:17.

31. Stuart CH, Singh R, Smith TL, D'Agostino R Jr, Caudell D, Balaji KC, Gmeiner WH. Prostate-specific membrane antigen-targeted liposomes specifically deliver the $\mathrm{Zn}(2+)$ chelator TPEN inducing oxidative stress in prostate cancer cells. Nanomedicine. 2016;11:1207-22.

32. Mauriz JL, Gonzalez-Gallego J. Antiangiogenic drugs: current knowledge and new approaches to cancer therapy. J Pharm Sci. 2008;97:4129-54.

33. Tseng FJ, Chen YC, Lin YL, Tsai NM, Lee RP, Chung YS, Chen CH, Liu YK, Huang YS, Hwang CH, et al. A fusion protein with the receptor-binding domain of vascular endothelial growth factor-A (VEGF-A) is an antagonist of angiogenesis in cancer treatment: Simultaneous blocking of VEGF receptor-1 and 2. Cancer Biol Ther. 2010;10:865-73.

34. Liu YK, Lin YL, Chen CH, Lin CM, Ma KL, Chou FH, Tsai JS, Lin HY, Chen FR, Cheng TL, et al. A unique and potent protein binding nature of liposome containing polyethylenimine and polyethylene glycol: a nondisplaceable property. Biotechnol Bioeng. 2011;108:1318-27.

35. Lin YL, Chen CH, Liu YK, Huang TH, Tsai NM, Tzou SC, Liao KW. Lipo-PEGPEl complex as an intracellular transporter for protein therapeutics. Int J Nanomedicine. 2019;14:1119-30.

36. Lin YL, Tsai NM, Chen CH, Liu YK, Lee CJ, Chan YL, Wang YS, Chang YC, Lin $\mathrm{CH}$, Huang $\mathrm{TH}$, et al. Specific drug delivery efficiently induced human breast tumor regression using a lipoplex by non-covalent association with anti-tumor antibodies. J Nanobiotechnology. 2019;17:25.

37. Saqafi B, Rahbarizadeh F. Polyethyleneimine-polyethylene glycol copolymer targeted by anti-HER2 nanobody for specific delivery of transcriptionally targeted tBid containing construct. Artif Cells Nanomed Biotechnol. 2019;47:501-11.

38. Khan N, Bammidi S, Jayandharan GR. A CD33 antigen-targeted AAV6 vector expressing an inducible caspase-9 suicide gene is therapeutic in a xenotransplantation model of acute myeloid leukemia. Bioconjug Chem. 2019;30:2404-16.

39. Ulbrich K, Hola K, Subr V, Bakandritsos A, Tucek J, Zboril R. Targeted drug delivery with polymers and magnetic nanoparticles: covalent and noncovalent approaches, release control, and clinical studies. Chem Rev. 2016;116:5338-431.

40. Nobs L, Buchegger F, Gurny R, Allemann E. Current methods for attaching targeting ligands to liposomes and nanoparticles. J Pharm Sci. 2004;93:1980-92.

41. Tseng FJ, Liu YK, Chung YS, Lin YL, Chen CH, Wang WY, Chen YC, Tsai NM, Cheng TL, Pan RY, et al. A fusion protein composed of receptor binding domain of vascular endothelial growth factor-A and constant region fragment of antibody: angiogenesis antagonistic activity. Cytotechnology. 2011;63:285-93.

\section{Publisher's Note}

Springer Nature remains neutral with regard to jurisdictional claims in published maps and institutional affiliations. 